\title{
Genomics and a Scientifically Responsible Ethics
}

\author{
Sydney Brenner \\ King's College, Cambridge CB2 1ST, UK
}

Genomics is a field where almost every sentence begins with the words 'we will be able to...' When dealing with the ethics of the field, one must distinguish very carefully between impotence and chastity; it is important to distinguish between 'can't' and 'won't'.

The history leading up to our current situation on the basic scientific level is well known, but is worth recalling for context. In 1953, Watson and Crick published a paper in which they showed the familiar icon of our times, the double helical structure of DNA. For the first time, one could see a solution to major problems of biology and especially to major problems of genetics. More particularly, we could begin to study the chemistry of information. Chemistry, of course, could also be called very low energy physics; and so for the first time we were on the verge of a physical analysis of information in biology. As is well known, biological systems are unique complex systems in the universe in that they carry an internal description of themselves in the form of their genes. No other complex system has this property. The weather is a complex system, but you can't clone the weather because there is no physical internal description.

We very quickly came to learn what genes were, what genes did, and how the information was passed from the gene to the workhorses of the cell which are the proteins. In the space of a decade, we worked out this fundamental biochemistry.

The next major revolution took place in the mid 1970s. It was grounded in two technical developments. The first was a method of cloning DNA: that is, of taking DNA out of any organism, putting it into other pieces of DNA called vectors and then propagating these pieces inside micro-organisms. This technology meant that one could take the genome, that is, all the genetic material of any organism, and create a library of fragments, thus gaining direct access to the genome. The second technical development, which we owe to Fred Sanger, was a method of directly analysing the chemical structure of these pieces, namely, DNA sequencing.

By 1985, it was not difficult to imagine that we could determine the entire structure of the human genome. That was quite a dramatic ambition to have at the time, since the human genome contains 3,000 million base pairs. The biggest genome that had been sequenced

Sydney Brenner worked at the Cavendish Laboratory in Cambridge, and its successor, the MRC Laboratory of Molecular Biology in Cambridge, from 1956 to 1987, when he became Director of the MRC Unit of Molecular Genetics, retiring in 1992. In 1996 he took up the position of President and Director of Science at the Molecular Sciences Institute, Berkeley, California, stepping down in 2001. His work led the way toward the first genetic mapping of a multicellular organism and contributed to the development of the Human Genome Project. In 2002 he was awarded the Nobel Prize in Physiology of Medicine, together with John Sulston and Robert Horvitz, for this work.

1 This article is based upon remarks offered at the opening of the BIOS Centre at the LSE, June 2003. 
was a bacterial virus with about 50,000 base pairs, so sequencing the human genome would be a task that was many orders of magnitude larger. But with technical advances, a few months ago the final, really final human genome sequence was declared completed.

The first public impact of this research actually came early in the mid 1970s when scientists discovered that they could clone DNA and also then alter the genetic constitution of organisms by what was called genetic engineering. The question was asked: was this dangerous? This question for me had a certain irony since, when I began working in molecular biology, it was seen as a completely useless science. In fact, Sir Ernst Chain, one of the inventors of penicillin, tried to get all funding stopped for the field in the UK on the grounds that we hadn't cured anybody. The best defence I could come up with was that we also hadn't killed anybody. Now, suddenly, we had gone from being a science that some wanted to suppress because it was useless to one that people wanted to control because it was dangerous. It takes something to end up both useless and dangerous. This was also an interesting period for the scientific community of biologists because, for many, it was the first time they had been exposed to issues of public concern and the various scenarios that were being propagated by the media and others outside the scientific enterprise. The tenor of the time was quite alarmist: molecular biology was supposed to be very dangerous, potentially poised to change the whole path of human evolution, and therefore something we should stop.

I participated in many of the discussions at the time and I learnt something about what people at the time were calling ethics. What became clear to me, though, was that the socalled ethical debate was really a political debate. The distinction is quite important. Politics here distorts a process that needs really to be done properly and rationally; namely, riskbenefit analysis. Indeed, the most important person involved in the process-the man in the street-really does not understand how to do it; because he does not understand probability. Scientists have been told that they need to be socially responsible. But society equally needs to be scientifically responsible when it comes to assessing the risks of research. The two responsibilities need to go together.

Three case studies may help make these points more clearly. The first is one that everybody knows about: genetically modified (GM) food. The GM story began with the development of techniques that allowed people to put genes from bacteria into the genomes of crop plants. It was known that some bacteria had evolved a protective mechanism-a proteinthat had killed any mosquito larvae that tried to feed on them. In this sense, the protein acted as a natural insecticide for the bacteria. People asked: why don't we insert the gene responsible for making this particular protein into a plant? It should have the effect of killing any insects that eat it, and allow us to cut down on our use of unnatural chemical insecticides. This was done using a method that involved coupling the gene to a genetic marker for drug resistance. Some people opposed this at the time arguing that we would be eating plants that carry such a genetic marker, with unknown consequences for health.

The problem with efforts to assess the harmfulness of GM food is that the arguments against GM are all based on scenario thinking. From a scientific point of view, scenario thinking is the worst form of risk assessment because there's no basis for comparison. In other words, rather than merely arguing that you're in a tree off the ground, you need to say what height you're at; that is, how this risk compares to other risks that we as a society may or may not consider acceptable. A scientist can say that there's a very low probability of harm, and when you ask 'How low?' he'll argue 'Very low,' but he won't give a number 
because of the politics in play here-he wants to leave an opening for himself in case something does happen. And certainly most scientists are unwilling — until they reach my age-to say that they believe something is completely harmless. When you reach my age, you're willing to go out on a limb because you realize that the matter won't be resolved in your lifetime, and the consequences do not matter when you're dead. So, for the record, I'm quite happy to say that GM food, for example, is completely harmless.

In thinking properly about how to calculate risk and benefit, the most important thing to realize in the first instance is that, when the benefit is zero, then of course the risk, however tiny, is infinite, because any number divided by zero gives you infinity. If I had been in charge of introducing GM food to the public, I would not only have labelled the food as genetically modified; I'd also have charged more for it. I would have put up a sign that said that this extra money we are paying will go into a fund, into which the company will also put its patents, to be used to develop tropical agriculture and address world hunger. This would have provided a benefit of GM food, and I think many people might well have been prepared to accept it. Instead, we currently face a ludicrous situation in which any risks of GM fail to be weighed properly against other risks, with countries like Zambia preferring to face famine in preference to eating GM food with minuscule risks. Something does not add up here, and this underscores the importance of moving the debate away from the politics of GM and towards a rational risk-benefit analysis.

Similar kinds of irrational calculations are at play when it comes to the area of so-called probabilistic or personalized medicine. We all know that humans are very diverse. There's the person who eats a huge amount and never gets fat or develops heart disease; there are also the people who claim they eat virtually nothing and yet put on weight relentlessly. At least part of this variation has a genetic basis. This is not unreasonable, since our genes are basically inherited from people who survived the last Ice Age, a time when it would have made sense to store up as much fat as you can during the good times so that you could survive the long winter of scarcity. In our own time, of course, that winter never arrives.

This leads to situations such as one sees in the Native American population in Arizona. The people there weigh in excess of 250-300 pounds and 50\% of them suffer from Type 2 diabetes. A century ago, however, individuals with the same genome as the current population were lithe and fit. What has changed is not the genetics, but the circumstances in which they find themselves. After about 1912, irrigation began to destroy their former way of life, they all now live on welfare and everything they eat is deep fried. Under these new circumstances, a long-standing genetic predisposition to hold onto fat stores-adaptive in a lean lifestyle-revealed itself in new unhealthy ways.

What if there are many different kinds of genes that predispose to many different kinds of illnesses? That is a question people are asking; they haven't yet found very many of them but are working on the assumption that they will be found. What are the consequences of seeking such information? Most importantly, who should have access to it? One sees immediately what is at stake. Suppose a health insurance company in the United States gets its hands on the data, discovers that a subset of its applicants are susceptible to heart disease and then either refuses them health insurance or offers them insurance at a higher rate. What do we think about this? Should this information be secured as private to protect people against what we can call 'genetic discrimination'? While we're at it, let's not forget that there is a whole class of persons in our society-women-who have, for a very long 
time, been genetically discriminated against on the grounds that they have two copies of the $\mathrm{X}$ chromosome. Are we now looking at a new world in which genetic discrimination becomes increasingly varied and targeted? Should we develop legislation on this matter to preserve privacy and ensure non-discriminatory practices? What are our options?

Again, a sound response demands that we first think clearly about the science here. We are dealing here with forms of susceptibility that are only probabilistic. Unlike inheriting a late-developing disease like Huntington's where one is certain to succumb (and it is only a question of whether one gets it at 40 years or 50), here there is no certainty but only a statistical probability-the average number of individuals in a target group getting some or other disease. If you tell a patient, ' $60 \%$ of people with your condition will be cured with this treatment,' the patient immediately asks you, 'Doctor, am I in the $60 \%$ or the $40 \%$ group?' The idea of probability means nothing to him; and nor should it. The concept only has meaning for social institutions: government departments and insurance companies that care about the statistical values but do not care about any specific individuals dying or not of heart disease. The individual, on the other hand, does understand gambling. We should say to him: 'I've looked at your genome, and I can tell you that you have a $90 \%$ chance of dying of cardiac disease by the age of 60 . However, if you stop watching television, and start exercising and eating properly, give up McDonald's, go through all these remedial therapies, then your chance of dying will fall from $90 \%$ to $5 \%$.' In this way, applying practical medical ethics, you've given him a way of engaging actively with the potential outcomes created by his individual genome. In other cases, where there is nothing an individual can do to alter the susceptibility that gives a person a $60 \%$ chance of becoming schizophrenic in 20 years' time-it's just research without any immediate social benefit. In this sense, there's no point in making a map of such genetic susceptibilities because there is no information upon which the individual may act.

Are the practical ethics of testing for genetic susceptibilities any different from those when a doctor takes my blood pressure to get some sense of my susceptibility for heart disease? Aren't we just talking about another test? No, there is an important difference. When a doctor takes a patient's blood pressure, he's learning something about the patient as he is at that moment. If the blood pressure is normal, no interventions are justified. We are talking now about testing someone whose current state of health may be perfect, but whose genetic profile basically foretells his future. It's a kind of biological horoscope; sometime I call it a genoscope. This takes us to the larger question of who-beside the patient himself-should have access to the futures of individuals? Do insurance companies have any rights to such information? I think not. It's fair that they take a history: hstory is about your past, about your parents, and it might tell you something about your genetic susceptibilities. I also think it is fair to examine you to assess your present health. However, access to your probable future should not be permitted; it gives them an extra margin to which, I believe, they are not entitled. There is nothing complicated, I think, about these matters; nothing that requires us to become embroiled in what one can call grand ethics. We are simply trying to define rational grounds for practical social decisions.

My third case concerns cloning, another common topic of current ethical debate. Again, matters are considerably clouded by the fact that people are not very clear about what cloning means. Someone in the audience of a lecture I once gave asked me: 'Why shouldn't I be allowed to clone myself and keep the copies as spare parts?' My response was: 'Be 
careful, one of the copies might decide to keep you for spare parts!' This is the first time that I realized that many people think about clones, not as individual persons in their own right, but as objects that one can sort of hang in a cupboard and cut off pieces every time one needs another finger or other body part. In fact, the decision to make a clone of yourself is actually a decision to create your twin brother or sister, who will be a generation or more younger than you, and growing up in a completely different environment. It's not a spare version of you, a copy of you. We must distinguish very carefully between genomes and bodies on the one hand, and the persons they become on the other. We are all much more than our genomes. We are our memories and experiences as well. Identical twins do not have identical immunological reactions because each twin has had a different pattern of interaction with foreign agents in the environment. That's how fundamental the experiential dimension can be, and underscores the difference between genomes and persons. If we want to create clones of persons, we already have methods at our disposal: they are calls armies and schools, making everybody conform to a standard behaviour. When I look at soldiers, I sometimes think that once the authorities clone the minds, the bodies follow anyway: soldiers all look alike.

The positive rationale for cloning is that some types of cloning could be a basis for what is called regenerative medicine, based on the idea that we might actually be able to repair people. If someone has damaged neurons from Parkinson's disease, we might be able to replace them with good neurons. We already transplant organs, but because each individual has a unique immunological identity, we cannot transplant tissues freely between different people because their bodies are likely to reject the foreign tissues. If we took any available stem cell line and tried to use it as the basis for regenerative medicine, this would fail because the body would reject the cells as foreign. If, however, we cloned individuals just up to the point at which we could make stem cells from the very early embryo, then one would have here specialized stem cells that could be used for that individual but, of course, for not many others.

Should we encourage this sophisticated medicine? How are we to judge the ethical imperatives in this research? I think that the answer has to be that we must consider the whole of humanity in our thinking. At the end of the day, the human ills in southern California are quite different from those in Africa. The SARS epidemic killed fewer people than those who die of malaria in three days. The HIV epidemic in Africa will result in 45 million deaths. Yet we know that research and healthcare delivery are not driven by utilitarian calculations designed to maximize the greatest good for the greatest number. They are driven by pharmaceutical companies, themselves driven by the profit motive, who have concluded that people in Africa have another disease called money deficiency disease, and that it's therefore not worth trying to produce cures for them.

Is there some way that the new molecular biological and genetic research might offer a basis for a different kind of healthcare system-a more humanitarian system? Pharmaceutical companies already are becoming like the dinosaurs, getting larger and less fit; and eventually they may find that they have nothing left to do, and go extinct. The reason is that pharmaceutical companies cannot deliver stem cell therapies, just as they cannot deliver cardiac transplants. Such techniques will have to be delivered through completely different social institutions, which we need to invent. I think it is worthwhile to examine the likely 
economic and the other societal changes that could accompany changes in the way we might think about health research and healthcare in the next 25-30 years.

I once said that what we need to do is tell people that they do not own their bodies; they have merely leased them from the human germline. If they're not prepared to look after them, then they could be taken away from them. Of course we can't do that, but we could envisage a time in which we might think differently about the moral responsibility of a person to look after his or her body. Today, most people believe they can do what they like to their bodies and when they get ill, the pharmaceutical industry will be there with a pill to fix everything.

This suggests a future in which our new knowledge about ourselves produces what might call the new public health. In the nineteenth century, the most important step in advancing human health was the separation of the water one drank from the water one excreted. Perhaps we are now on the brink of creating a new public health that will treat all of humanity and redefine the relationships between individual persons, the bodies they inhabit and the societies they create. 